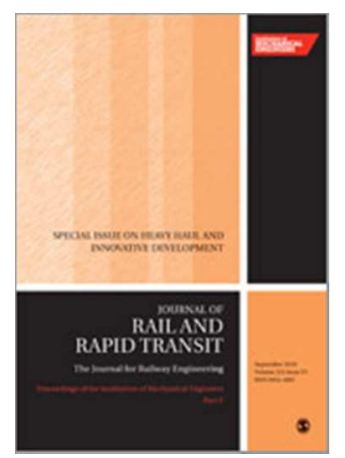

\title{
Simulation of Braking Performances: the application on Ansaldobreda EMU V250
}

\begin{tabular}{|c|c|}
\hline Journal: & Part F: Journal of Rail and Rapid Transit \\
\hline Manuscript ID: & JRRT-13-0041.R2 \\
\hline Manuscript Type: & Case Study \\
\hline Date Submitted by the Author: & $18-J u l-2013$ \\
\hline Complete List of Authors: & $\begin{array}{l}\text { pugi, luca; University of Florence, DIEF-MDM LAB } \\
\text { Malvezzi, Monica; University of Siena } \\
\text { papini, susanna; University of florence, dip. industrial engineering } \\
\text { tesi, simone; Ansaldobreda, }\end{array}$ \\
\hline Keywords: & $\begin{array}{l}\text { Rail Vehicles, Tribology, Applied Mechanics, braking, friction factor, Railway } \\
\text { Vehicle, Railway Technology/ Engineering }\end{array}$ \\
\hline Abstract: & $\begin{array}{l}\text { This paper presents the development of a modular tool for the prediction } \\
\text { of train braking performance. A particular attention is devoted to the ac- } \\
\text { curate prediction of stopping distances, considering di } \\
\text { erent loading and } \\
\text { operating conditions, necessary to verify safety requirements prescribed by } \\
\text { the European Technical Specications for Interoperability of High Speed } \\
\text { Trains (TSI-HS) and the corresponding EN regulations. Results are ver-ied } \\
\text { by considering, as a benchmark, the AnsaldoBreda EMUV250: an } \\
\text { European train being developed for Belgium and Netherlands high speed } \\
\text { lines. Technical information and experimental data were available for this } \\
\text { train, directly recorded during preliminary supplier exercise. Validation } \\
\text { results were encouraging, and allowed a more accurate identication of } \\
\text { the pad friction factor influence on braking performance }\end{array}$ \\
\hline
\end{tabular}

\section{SCHOLARONE \\ Manuscripts}




\title{
Simulation of Braking Performance: the AnsaldoBreda EMU V250 application
}

\author{
Luca Pugi $^{1}$, Monica Malvezzi ${ }^{2}$, Susanna Papini $^{1}$ \\ Simone Tesi ${ }^{3}$ \\ ${ }^{1}$ Dept. of Industrial Engineering, University of Florence, Florence, Italy \\ 2 Dept. of Information Engineering, University of Siena, Siena, Italy \\ ${ }^{3}$ AnsaldoBreda SPA, Pistoia, Italy
}

July 18, 2013

\begin{abstract}
This paper presents the development of a modular tool for the prediction of train braking performance. A particular attention is devoted to the accurate prediction of stopping distances, considering different loading and operating conditions, necessary to verify safety requirements prescribed by the European Technical Specifications for Interoperability of High Speed Trains (TSI-HS) and the corresponding EN regulations. Results are verified by considering, as a benchmark, the AnsaldoBreda EMUV250: an European train being developed for Belgium and Netherlands high speed lines. Technical information and experimental data were available for this train, directly recorded during preliminary supplier exercise. Validation results were encouraging, and allowed a more accurate identification of the pad friction factor influence on braking performance.
\end{abstract}

Keywords: Braking performance, Braking pad friction, numerical simulations.

\section{Introduction}

Braking performance are a safety relevant aspect, impacting vehicle longitudinal dynamics, signaling and traffic management. Braking system performance and requirements are quite important also for interoperability issues [1] and corresponding regulations in force. In particular, TSI (Technical Specifications for Interoperability) regulations prescribe an accurate analysis and verification of braking systems performance, considering some degraded and critical cases and worst operating conditions, whose statistical occurrence should be quantified [2]. The safety level required in this type of application is very high and its impact is important, both on construction and maintenance costs, so this system has to be carefully designed and optimized. This paper describes a part 
of a time-extended cooperation between AnsaldoBreda group with University of Florence, on the development of an integrated approach providing the harmonized use of different engineering tools, embracing complementary aspects of the problem:

- Macroscopic occurrence of braking performance and failure: assigning a statistical occurrence to each failure source, an extended population of possible configurations (several millions) is generated, in order to give a macroscopic reliability evaluation of the system performance. Due to the complexity of these models the computation resources has to be optimized $[3,2]$.

- Train braking performance simulation: this intermediate level model of the whole braking system is used to simulate train braking performances and identify some system parameters from a limited population of inline experimental tests. The provided information about statistical occurrence of braking degradation can be used to tune the aforementioned statisticalmacroscopic model.

- Detailed system models: brake system components can be simulated with specific mathematical models, able to describe in details the effects of each single failure. In the literature some works can be found concerning this kind of analysis for pneumatic system and components [4], [5], [6], about the testing of complex brake system such as WSP [7] or elementary components such as brake pads [8],[9].

EN 14531 [10] provides indications concerning preliminary calculation of braking performances giving a general work-flow that can be adapted to different vehicle categories:

- Freight wagons;

- Mass Transit;

- Passenger Coaches;

- Locomotives;

- High Speed Trains ;

The aim of this regulation is to set a general method that should be shared among different industrial partners (industries, railway operators, safety assessors,etc.). In this paper a tool called TTBS01, developed in Matlab ${ }^{T M}$, is described. It implements the method for the calculation of braking performances described by [10] and successfully validated on experimental results concerning AnsaldoBreda EMU V250 [11],[12]. Since the detailed description of the calculation method is directly available on the reference regulation [10], in this work a more general algorithm description is provided, focusing the attention on the test case, the numerical results, the critical issues arisen the validation activities, 
and finally to some optional features which could be used to further increase the result accuracy, identifying some parameters, such as braking pad friction factor, that should be slightly variable according different operating conditions.

\section{The test case: EMU V250}

The tool described in this paper TTBS01 was tested and validated on the AnsaldoBreda EMU V250 train, an High Speed Electrical Multiple Unit for the passenger transport with a maximum operating velocity $250 \mathrm{~km} / \mathrm{h}$ (maximum test speed $275 \mathrm{~km} / \mathrm{h}$ ), composed of 2 train sets of 8 coaches. Traction is distributed, with alternating motor and trailer vehicles in this sequence: MTMTTMTM (where letter $\mathrm{M}$ is used to represent motorized coaches, while $\mathrm{T}$ the trailer ones). Its composition is shown in Figure 1.

The traction motors of the motorized coaches (wheelset B0-B0) can be used for electro-dynamic braking, both regenerative and dissipative. The 2nd and the 7th coach of the composition are equipped with an Electro-Magnetic Track Brake that should be used in emergency condition.

The mandatory pneumatic braking systems is an electro-pneumatic one; both direct and indirect electro-pneumatic operating mode are supported, so the braking command should be directly transmitted by wire to the BCU (Braking Control Unit) on each coach or indirectly by controlling the pressure of the pneumatic pipe using the system shown in the simplified scheme in Figure 2. Finally there is backup mode in which the brake is controlled as a standard pneumatic brake assuring interoperability with vehicles equipped with a standard UIC Brake.

Each axle is equipped with brake discs: three for the trailing axles (shown in Figure 3 ), two for the motorized ones, where also electric braking is available. In this configuration magnetic track brake should be available since the track lowering is controlled by a pressure switch also commanded using the brake pipe (absolute pressure threshold at 3 Bar). The corresponding pneumatic brake system configuration and the inertia parameters adopted for the calculations are summarized in Tables 1 and 2.

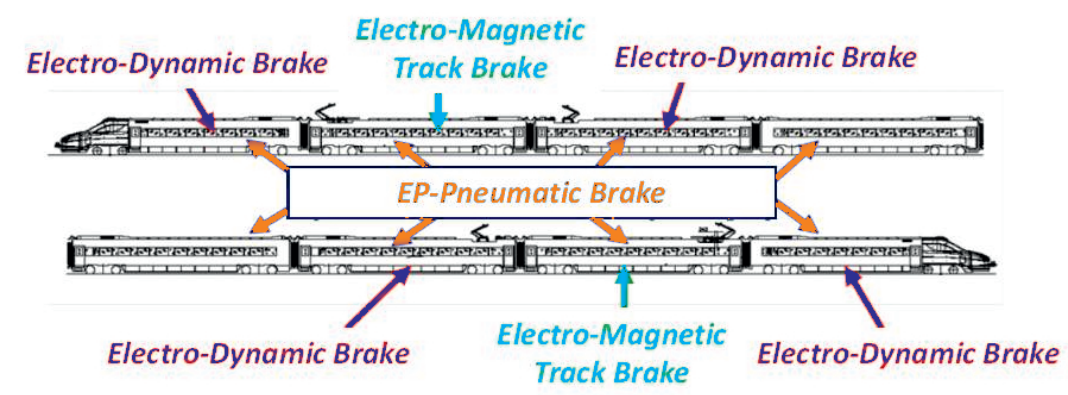

Figure 1: Emu V250 vehicle composition and braking system layout [9]. 


\begin{tabular}{|c|c|c|c|c|c|c|}
\hline $\begin{array}{c}\text { Coach } \\
\text { Bogie }\end{array}$ & $\begin{array}{c}\text { VOM load } \\
\text { (tare }[\text { tons] }]\end{array}$ & $\begin{array}{c}\text { TSI load } \\
\text { tons] }\end{array}$ & $\begin{array}{c}\text { CN Load } \\
(\text { nom. })[\text { tons] }\end{array}$ & $\begin{array}{c}\text { CE load. } \\
(\max )[\text { tons] }]\end{array}$ & $\begin{array}{c}\text { bogie mass } \\
{[\text { tons] }}\end{array}$ & $\begin{array}{c}\text { equiv. rot. } \\
\text { masses [tons] }\end{array}$ \\
\hline \hline M1-1 & 15.9 & 16.7 & 17 & 17.6 & 9.93 & 1.5 \\
\hline M1-2 & 13.9 & 15 & 15.4 & 16.3 & 9.81 & 1.5 \\
\hline T2-3 & 13.9 & 15 & 15.3 & 16.6 & 7.85 & 0.6 \\
\hline T2-4 & 14 & 15.1 & 15.4 & 16.5 & 7.85 & 0.6 \\
\hline M3-5 & 13.6 & 14,8 & 15.2 & 16.1 & 9.81 & 1.5 \\
\hline M3-6 & 14.1 & 15.5 & 15.9 & 16.8 & 9.81 & 1.5 \\
\hline T4-7 & 11.2 & 12.8 & 13.3 & 14.2 & 7.85 & 0.6 \\
\hline T4-8 & 12.1 & 13.7 & 14.2 & 15 & 7.85 & 0.6 \\
\hline T5-9 & 12 & 13.6 & 14.1 & 14.9 & 7.85 & 0.6 \\
\hline T5-10 & 11.3 & 12.8 & 13.2 & 14.1 & 7.85 & 0.6 \\
\hline M6-11 & 14.1 & 15.7 & 16.2 & 17 & 9.81 & 1.5 \\
\hline M6-12 & 13.8 & 15.3 & 15.8 & 16.7 & 9.81 & 1.5 \\
\hline T7-13 & 14 & 15.6 & 16.1 & 16.9 & 7.85 & 0.6 \\
\hline T7-14 & 14.1 & 15.6 & 16.1 & 17 & 7.85 & 0.6 \\
\hline M8-15 & 13.7 & 15.2 & 15.7 & 16.5 & 9.81 & 1.5 \\
\hline M8-16 & 15.9 & 16.9 & 17.2 & 17.8 & 9.93 & 1.5 \\
\hline \hline Train Mass & 435.2 & 478.6 & 492.2 & 520 & & \\
\hline tons] & & & & & & \\
\hline \hline Train Rot. & & & & & & 33.6 \\
Masses [tons] & & & & & & \\
\hline \hline
\end{tabular}

Table 1: Vehicle loading conditions and inertia parameters for the braking model definition.

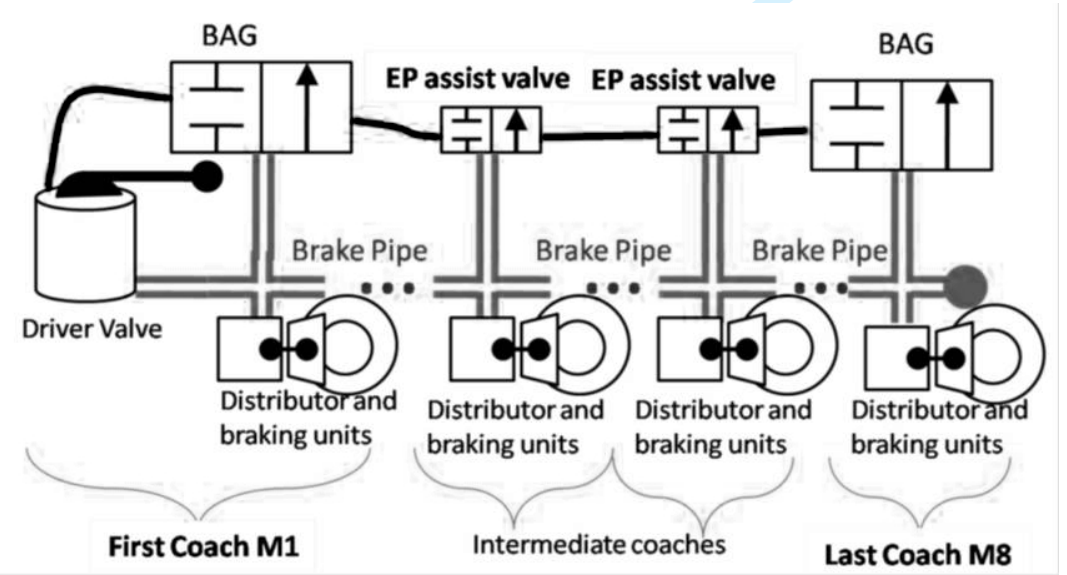

Figure 2: Braking system in the IEP mode. 


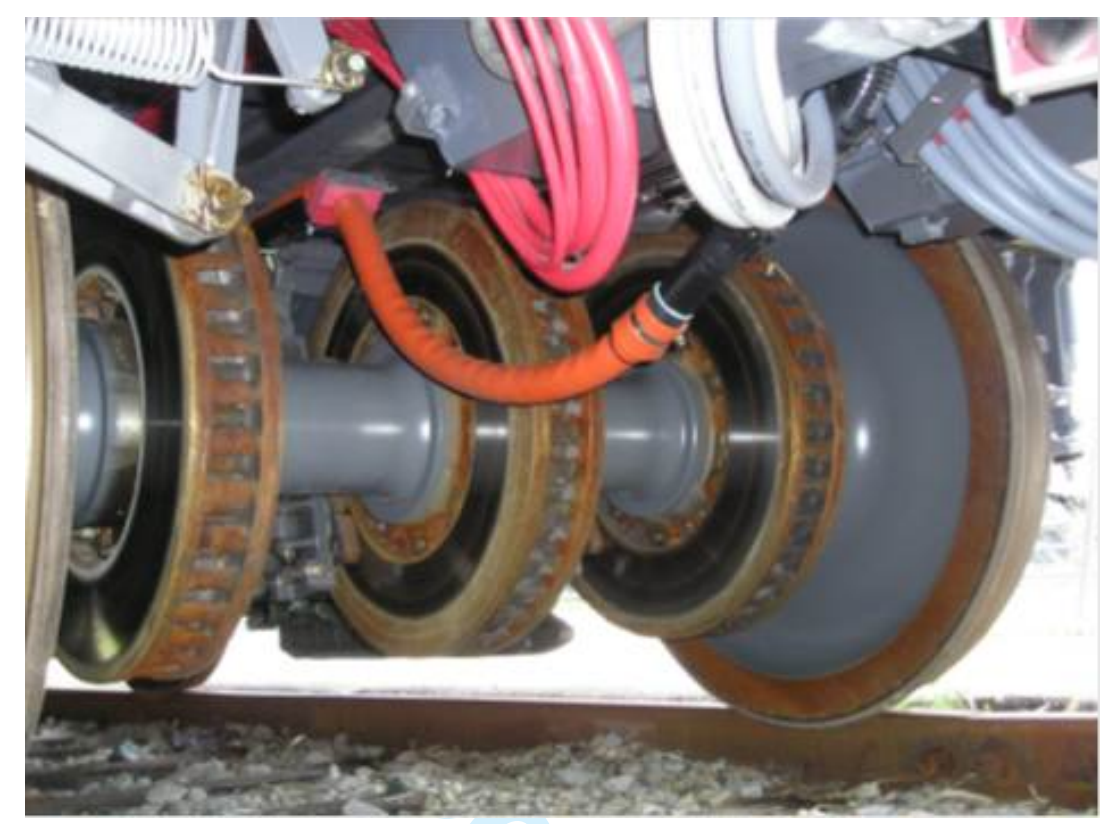

Figure 3: Brake discs on the trailer bogie [11],[12].

\begin{tabular}{|c|c|c|c|c|c|c|c|}
\hline $\begin{array}{c}\text { Coach } \\
\text { Bogie }\end{array}$ & $\begin{array}{c}\text { Wheel } \phi \\
\text { (new-worn) }[\mathrm{mm}]\end{array}$ & $\begin{array}{c}\text { Brake r. } \\
{[\mathrm{mm}]}\end{array}$ & $\begin{array}{c}\text { num. of } \\
\text { discs /axle }\end{array}$ & $\begin{array}{c}\text { Pad } \\
\text { Friction }\end{array}$ & $\begin{array}{c}\text { brake cyl. } \\
\text { surf. }[\mathrm{cm} 2]\end{array}$ & $\begin{array}{c}\text { Spring } \\
\text { force }[\mathrm{N}]\end{array}$ & $\begin{array}{c}\text { Caliper eff. } \\
\text { and ratio }\end{array}$ \\
\hline \hline M1-1 & $920-850$ & 299 & 2 & 0.42 & 506.7 & 1300 & 0.952 .82 \\
\hline M1-2 & $920-850$ & 299 & 2 & 0.42 & 506.7 & 1300 & 0.952 .82 \\
\hline T2-3 & $920-850$ & 243 & 3 & 0.42 & 506.7 & 1300 & 0.952 .69 \\
\hline T2-4 & $920-850$ & 243 & 3 & 0.42 & 506.7 & 1300 & 0.952 .69 \\
\hline M3-5 & $920-850$ & 299 & 2 & 0.42 & 506.7 & 1300 & 0.952 .82 \\
\hline M3-6 & $920-850$ & 299 & 2 & 0.42 & 506.7 & 1300 & 0.952 .82 \\
\hline T4-7 & $920-850$ & 243 & 3 & 0.42 & 506.7 & 1300 & 0.952 .69 \\
\hline T4-8 & $920-850$ & 243 & 3 & 0.42 & 506.7 & 1300 & 0.952 .69 \\
\hline T5-9 & $920-850$ & 243 & 3 & 0.42 & 506.7 & 1300 & 0.952 .69 \\
\hline T5-10 & $920-850$ & 243 & 3 & 0.42 & 506.7 & 1300 & 0.952 .69 \\
\hline M6-11 & $920-850$ & 299 & 2 & 0.42 & 506.7 & 1300 & 0.952 .82 \\
\hline M6-12 & $920-850$ & 299 & 2 & 0.42 & 506.7 & 1300 & 0.952 .82 \\
\hline T7-13 & $920-850$ & 243 & 3 & 0.42 & 506.7 & 1300 & 0.952 .69 \\
\hline T7-14 & $920-850$ & 243 & 3 & 0.42 & 506.7 & 1300 & 0.952 .69 \\
\hline M8-15 & $920-850$ & 299 & 2 & 0.42 & 506.7 & 1300 & 0.952 .82 \\
\hline M8-16 & $920-850$ & 299 & 2 & 0.42 & 506.7 & 1300 & 0.952 .82 \\
\hline
\end{tabular}

Table 2: Braking system main parameters. 


\subsection{Two-Stage Pressure and Load Sensing}

The pressure applied to brake cylinders and consequently the applied clamping and braking forces are regulated as a function of train mass (load sensing) and speed (two-pressure stage) mainly for the following reasons:

- load sensing: optimize the braking performances with respect to vehicles inertia and weight;

- two-pressure stage: protect friction components from excessive thermal loads;

- prevent over-braking (both the installed systems): according to the regulation [1] and the more recent [13], the braking forces applied to the wheels have to be limited in order to prevent over-braking, arising when brake application exceeds the available wheel/rail adhesion.

More in particular, braking forces are usually regulated, for example on freight trains, using a load sensing pressure relay whose simplified scheme is represented in Figure 4: a sensing device on primary suspension stage produces a pressure load signal, which is approximately proportional to axle load. The reference pilot pressure command, produced by the brake distributor, is amplified by the relay in order to fed brake cylinders using the leverage schematically represented in Figure 4. The system works as a servo pneumatic amplifier, with a pneumomechanic closed loop regulation, aiming at satisfy the following specifications:

- the limited pneumatic output of the brake valve has to be adapted to the corresponding brake cylinder flow requirements;

- the filling pressure of the brake cylinders has to be regulated with respect to the distributor output through a pressure gain.

The pressure gain is adjustable, since the pivot of the leverage and consequently the amplification ratio is regulated by the pressure load signal.

On freight trains, where the difference between the tare and full loaded masses of the vehicle could be in the order of 300\% (from 20-30 t/vehicle for the empty wagon to $90 \mathrm{t}$ /vehicle for the full loaded one), load sensing is very important. For high speed trains such as EMU V250 or the new high speed trains the difference between VOM and CE loading conditions as shown in Table 1 , should be sensibly lower, no more than $10 \%-20 \%$. As a consequence, the corresponding variation in terms of deceleration and dissipated power on discs often is not numerically very important, and is partially tolerated by regulation in forces [13] for high speed train with more than 20 axles, in emergency braking condition or in other backup mode, where the full functionality of the system should not be completely available. For safety reasons, the correct implementation of the two-stage pressure is much more important: a lower filling pressure of brake cylinders is applied for speeds over $170 \mathrm{~km} / \mathrm{h}$. In this way it is possible to satisfy the following requirements: 
- the energy dissipated during a stop braking increases approximately with the square of train traveling speed. By lowering braking clamping forces it is possible to reduce the instantaneous thermal power dissipated over a disc. A reduction of disc clamping forces may be fundamental to avoid the risk of excessive thermal loads, preventing friction component damages;

- adhesion limits imposed by [13] prescribe a linear reduction of the braking forces between 200 and $350 \mathrm{~km} / \mathrm{h}$ according to a linear law. As a consequence the implementation of the two-stage pressure helps to meet this requirement.

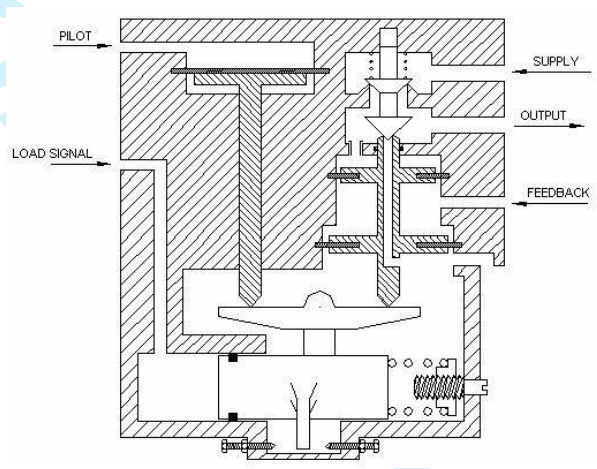

Figure 4: Pressure relay/load sensing device.

\subsection{Electrical Braking and Blending}

Electrical or electro-dynamical brake is a near to mandatory trend for a modern high speed train. Most of the more modern EMU trains have the traction power distributed over an high number of axles.

On EMU V250 train about $50 \%$ of the axles are motorized and about $55 \%$ of the total train weight is supported by motorized bogies. As a consequence, a considerable amount of the total brake effort should be distributed to traction motors, performing regenerative or rheostatic braking, according the capability of the overhead line of accepting the corresponding recovered power. In particular both regenerative and rheostatic electric braking are quite attractive, considering the corresponding reduction of wear of friction braking components such as pads and discs.

Since Electric Braking is applied in parallel to the conventional pneumatic one, an optimized mixing strategy in the usage of both systems, briefly called blending, has to be performed. In Figure 5, the electric braking effort available on a motorized coach is shown as a function of train traveling speed and of the electrification standard of the overhead line: three different operating region should be recognized: 
- Maximum pneumatic braking force: below a certain traveling speed, it is not convenient to apply electric braking. In particular at low traveling speeds, the amplitudes and the frequencies of the currents applied to the motors should are difficultly managed by static converters/power electronics of the traction system. On the other hand, the demanded braking power is quite low, so it can be completely managed by the pneumatic braking system.

- Minimum pneumatic braking: in this region, the electric braking effort is limited to a maximum level, often corresponding to a value of motors currents. If a higher braking effort is required, the pneumatic brake is activated to supply the needed difference.

- Pneumatic braking increases at high speed: as train speed increase, motor drive system performance is insufficient to manage the corresponding power requirements, limiting the maximum braking effort to the associated iso-power curve. As a consequence, the pneumatic braking power contribution tends to increase with speed to compensate the corresponding maximum braking torque reduction of the electrical one.

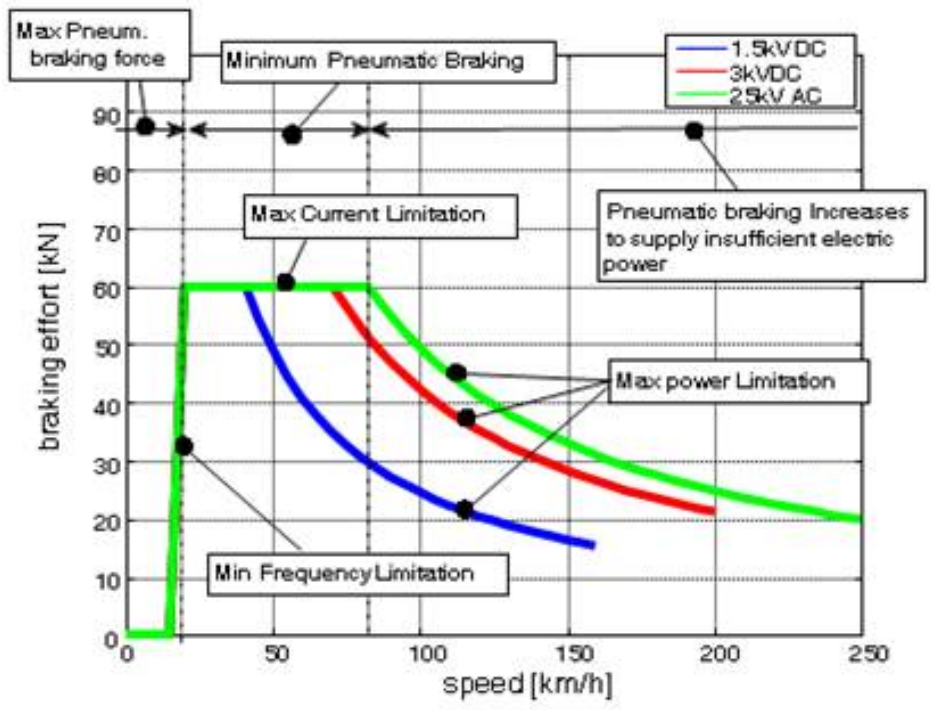

Figure 5: Typical behavior of electric and pneumatic braking effort on motorized bogies (from internal technical documentation of AnsaldoBreda). 


\section{Braking Regulations and Standards and the TTBS01 tool}

The EN 14531 (first draft 2003) describes the fundamental algorithms and evaluations for the design of brake equipment of railway vehicles. The regulation describes the calculation of the various aspects relative to braking performance: stopping or slowing distances, dissipated energy, force calculations, immobilization braking.

In particular, Part 6 is dedicated to high speed train application. It furthermore describes the general algorithms that have to be used to calculate stopping and slowing distances, including the input data representing train and brake main features.

The method proposed to calculate braking distance as a function of initial speed is based on deceleration estimation, calculated as the sum of different braking forces acting on the train. Obviously braking performances predicted according [10] should be in accordance with the experimental braking power calculated according UIC544-1 (4th edition October 2004) [14].

The braking performances prediction according [10] has been implemented in a tool called TTBS01, developed in the Matworks-Matlab ${ }^{T M}$ environment. A graphical user interface (GUI) also developed in Matworks-Matlab ${ }^{T M}$ is used to insert and modify input data, as shown in Figures 6 . The main parts of such tool are the following:

- Pre-processing (Import data): train data and simulation parameters are insert by the user;

- Configuration (Config): data are saved and stored in suitable files;

- Calculation: calculation is performed according EN 14531, the corresponding flowchart is reported in figure 6;

- Post-Processing: the user can view the representative brake output in several diagrams.

Since the proposed calculation method is completely described by the standard [10], this paper is more focused on the validation of the proposed tool and on the improvements that should be introduced in order to better fit experimental results and to better identify the friction behavior of brake pads respect to provided or supposed data.

It is worth to notice that the aim of the proposed software is not to substitute the methods proposed by existing standards, but rather to provide to the brake engineer some additional features and tools, to better understand some particular behaviors that can be observed on experimental data. 


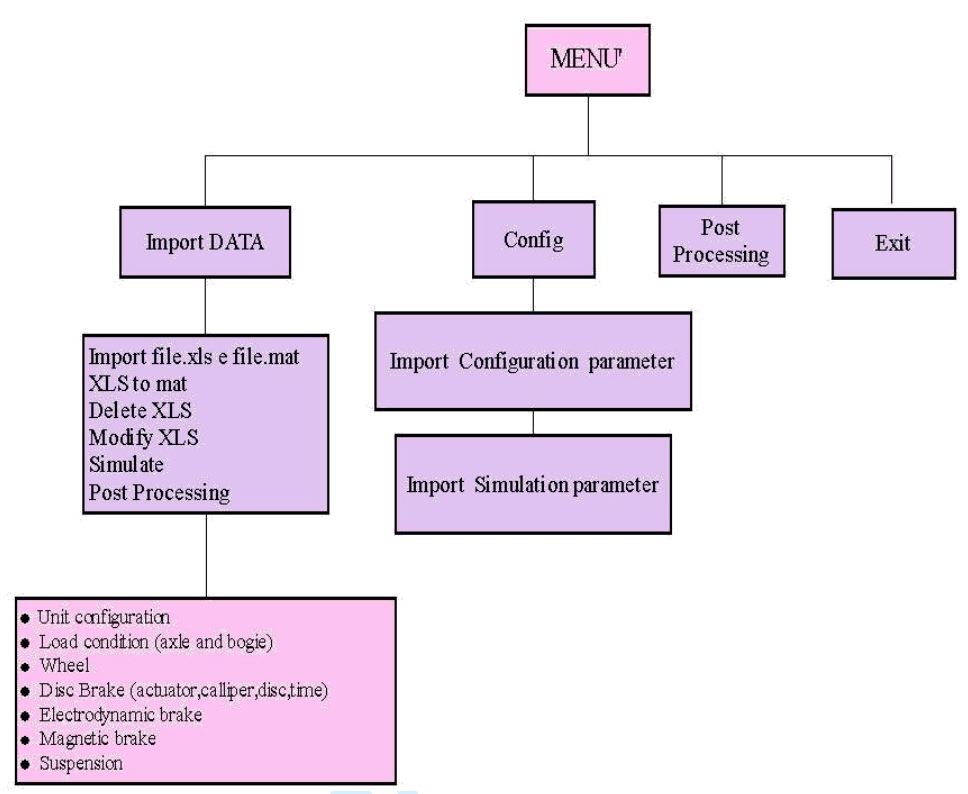

Figure 6: Interface structure of the TTBS01 tool.

\section{Preliminary Tool Validation}

The tool validation was carried out comparing simulation results with tests data [11], [12] which were performed considering various requirements of regulations in force. In particular, a population of about 50 experimental braking test runs was considered, they were performed on an train equipped with the sensor layout described in table 3.

\begin{tabular}{|c|c|c|c|c|}
\hline & $\begin{array}{c}\text { Pressure } \\
\text { Transducer }\end{array}$ & $\begin{array}{c}\text { Radar doppler } \\
\text { sensor }\end{array}$ & $\begin{array}{c}\text { Servo- } \\
\text { Accelerometer }\end{array}$ & $\begin{array}{c}\text { Temp. } \\
\text { Sensor }\end{array}$ \\
\hline Accuracy & $0.5 \%$ respect to full range & $\pm 1 \mathrm{~km} / \mathrm{h}$ & $0.1 \%$ respect to full range & Termocouple $\mathrm{K}$ \\
\hline Range & $0-12 \mathrm{bar}$ & $0-500 \mathrm{~km} / \mathrm{h}$ & $1 \mathrm{~g}$ & Termocouple $\mathrm{K}$ \\
\hline $\begin{array}{c}\text { Quantity } \\
\text { and Layout }\end{array}$ & $\begin{array}{c}8 \text { pressure transducer } \\
\text { on brake system }\end{array}$ & $\begin{array}{c}1 / \text { on a coach } \\
\text { carbody }\end{array}$ & $\begin{array}{c}1 / \text { on a coach } \\
\text { carbody }\end{array}$ & $4 /$ on \\
discs
\end{tabular}

Table 3: Sensor layout adopted for experimental test runs on EMU V250 $[11],[12]$.

The brake performance tests concern the emergency braking and service braking at several entry speed, also considering different working and operating conditions of the braking system (Direct Electropneumatic, Indirect ElectroPneumatic, Pneumatic, etc.). The tests runs were performed in normal adhe- 
sion condition, where WSP (Wheel Slide Protection) did not work. The test runs were performed on a complete V250 unit with coaches confirmed by single coach tests and with braking system (and all other subsystems involved in the braking functionality) fully working. The braking runs for the test procedure were performed in three different load conditions: VOM, TSI and CE as defined in [10]:

- VOM load condition is defined as mass empty, ready for departure;

- TSI corresponding to mass normal load;

- The CE load condition is defined as mass exceptional load.

\subsection{Acceptance criteria}

In order to verify and validate the TTBS01 simulation tool, the relative error $e_{s}$ as defined according to eq. (1) between the simulated stopping distance $s_{\text {simul }}$ and the experimental one $s_{\text {test }}$ was evaluated:

$$
e_{s}=\frac{s_{\text {test }}-s_{\text {simul }}}{s_{\text {simul }}}
$$

According [15],[16], the repeatability of braking performances in terms of mean deceleration has to satisfy the requirements summarized in Table 4, where the probability of having a degraded braking performance is summarized. The relative error on stopping-braking distance, for an assigned brake entry speed $v_{0}$, is approximately proportional to the deceleration, supposed to be constant and equal to the mean one, as stated in eq. (2):

$$
s=\frac{v_{0}^{2}}{2 a} ; \Rightarrow \frac{\partial s}{\partial a}=-\frac{v_{0}^{2}}{2 a^{2}} \Rightarrow \frac{\partial s}{s}=-\frac{\partial a}{a}
$$

\begin{tabular}{|c|c|c|c|c|c|}
\hline $\begin{array}{l}\text { Probability } \\
\text { (n.of tests) }\end{array}$ & $\begin{array}{l}10^{-1} \\
\left(10^{1}\right)\end{array}$ & $\begin{array}{l}10^{-2} \\
\left(10^{2}\right)\end{array}$ & $\begin{array}{l}10^{-3} \\
\left(10^{3}\right)\end{array}$ & $\begin{array}{l}10^{-4} \\
\left(10^{4}\right)\end{array}$ & $\begin{array}{l}10^{-5} \\
\left(10^{5}\right)\end{array}$ \\
\hline$\frac{\text { MeanDec. }}{\text { Nom.Dec. }}$ & $\begin{array}{c}0.969 \\
-3.1 \%\end{array}$ & $\begin{array}{c}0.945 \\
-5.5 \%\end{array}$ & $\begin{array}{c}0.926 \\
-7.4 \%\end{array}$ & $\begin{array}{l}0.905 \\
-9.5 \%\end{array}$ & $\begin{array}{c}0.849 \\
-15.1 \%\end{array}$ \\
\hline
\end{tabular}

Table 4: Statistic distribution of degraded braking performances according [15],[16].

Considering a test population of 50 test runs, an error between simulation and test results of about $4 \%$ was considered acceptable. Statistical distribution of Table 4 is referred to an homogeneous population of braking tests, but the campaign on EMU V250 was referred to a population in which each test was performed with different boundary and operating variables, so a higher variability of results with respect to expected simulation results should be expected. 


\begin{tabular}{|c|c|c|c|c|}
\hline Compostion & $1^{\text {st }}$ eigenfreq. & $2^{n d}$ & $3^{r d}$ eigenfreq. & $4^{\text {th }}$ eigenfreq. \\
\hline Standard (8 Coaches) & $2.4 \mathrm{~Hz}$ & $4.7 \mathrm{~Hz}$ & $6.9 \mathrm{~Hz}$ & $8.8 \mathrm{~Hz}$ \\
Doubled (16 Coaches) & $1.2 \mathrm{~Hz}$ & $2.4 \mathrm{~Hz}$ & $3.6 \mathrm{~Hz}$ & $4.8 \mathrm{~Hz}$ \\
\hline
\end{tabular}

Table 5: Calculated longitudinal eigenfrequencies of EMU V250 train, according to the model proposed in [10].

Some further considerations has to be done considering longitudinal train oscillations. In the experimental tests, it was observed, during the braking phase, a longitudinal mode at a frequency of about 1-2 Hz, which is measured by both speed and acceleration sensors and is also compatible with the results of a previous modal analysis [10], as visible in Table 5, and more generally to the typical longitudinal eigen-frequencies of train formations[17],[18].

In particular the phenomena is clearly recognizable on acceleration profiles visible in Figure 7. A qualitative comparison of experimental and simulation speed profiles with respect to the linear regression curve build on experimental data is shown in Figure 8.

This phenomena causes a variability on measured speed with respect to the mean value of about $1-2 \mathrm{~km} / \mathrm{h}$ (about $1-1.5 \%$ respect to brake entry speed). Considering the sensitivity of error on braking distance with respect to the correct evaluation of the brake entry speed, as calculated in (3), it produces an additional uncertainty on estimated braking distance of about $2-3 \%$

$$
s=\frac{v_{0}^{2}}{2 a} ; \Rightarrow \frac{\partial s}{\partial v_{0}}=\frac{v_{0}}{a} \Rightarrow \frac{\partial s}{s}=\frac{2 \partial v_{0}}{v_{0}}
$$

As a consequence, a level of acceptability of results of about 5-6\% was considered. This level of acceptability of test was also indirectly prescribed by UIC544-1 [14], which considers valid the result of braking test if the ratio $\sigma_{r}$ defined according (4) is lower than 0.03 for a population of four consecutive test runs.

$$
\sigma_{r}=\frac{\sigma}{s_{\text {mean }}}
$$

where $s_{\text {mean }}$ is the mean of measured braking distances and $\sigma$ is the standard deviation of measured braking distances.

Considering the definition of mean error and standard deviation, the condition in equation (3) should be used to evaluate the sensitivity of some measured variables of interests, such as braking distance, with respect to an admissible variability and tolerances on some test parameters such as measured brake entry speeds. In particular in this work a relative tolerance in the measurement of initial speed of $2-3 \%$ was used to justify a corresponding error of about $4-6 \%$ in the measured brake distance. 

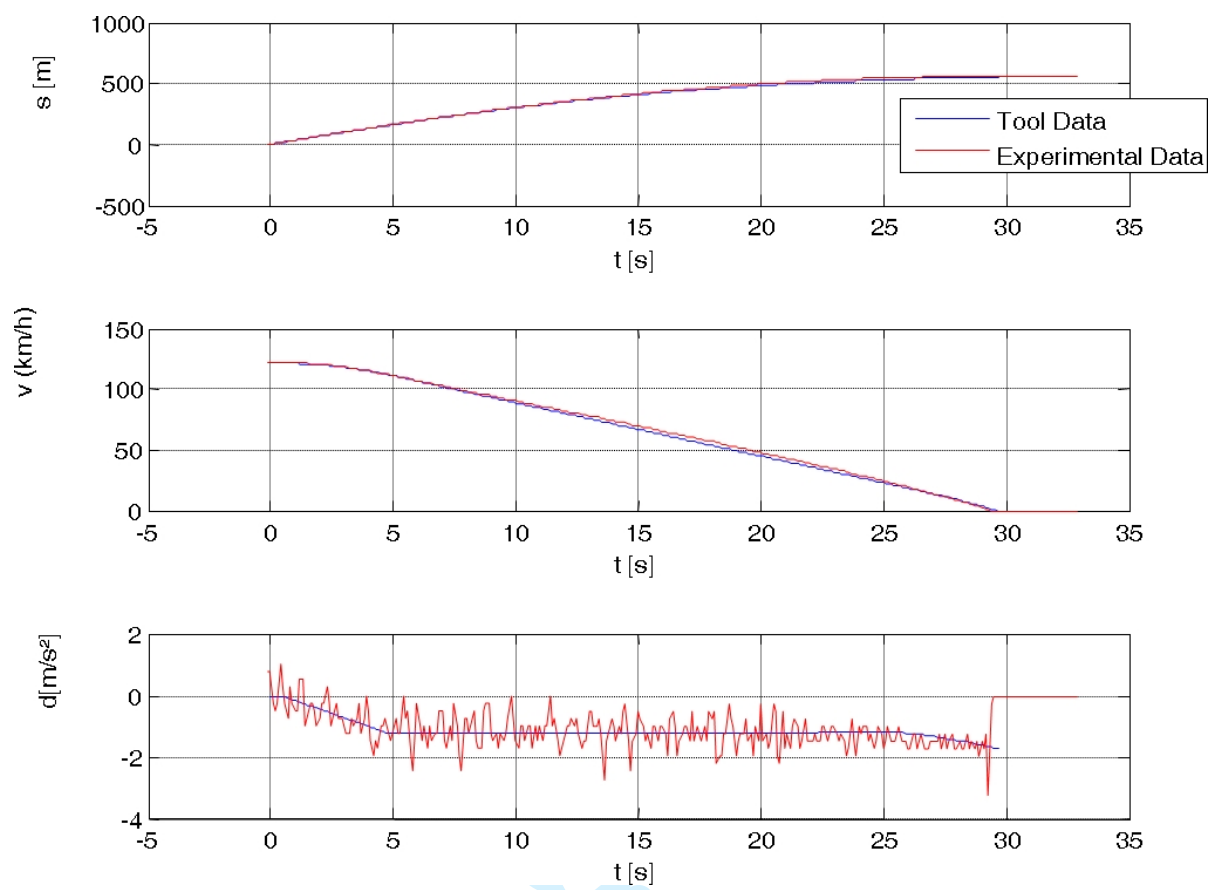

Figure 7: Space, speed and deceleration profiles measured and calculated during braking maneuvers.

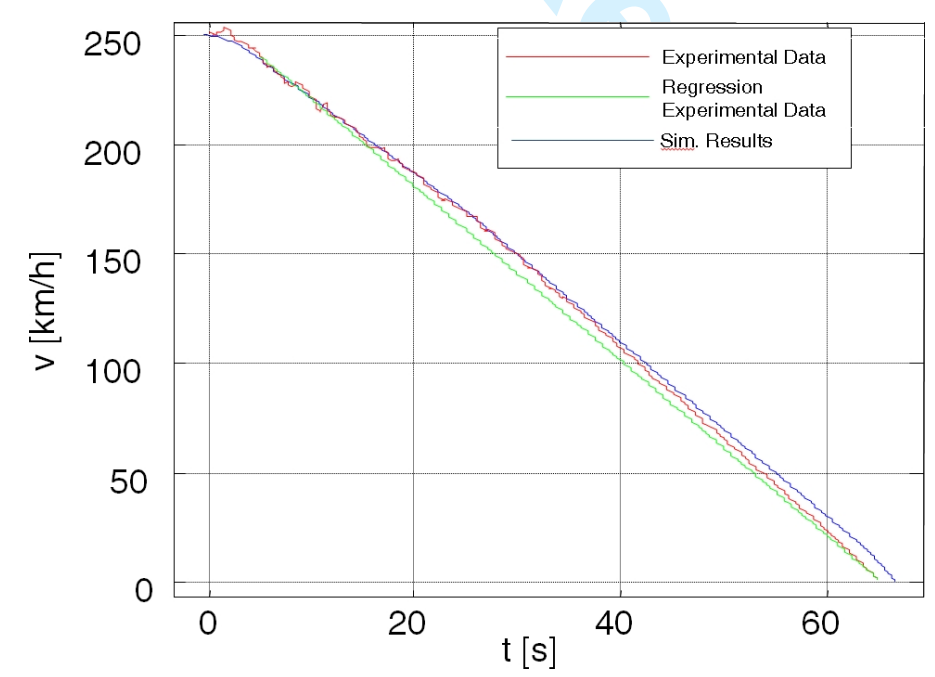

Figure 8: Comparison between experimental and simulated speed profiles respect to the the linear regression curve build on experimental data. 


\subsection{Identification of brake pads friction factor and prelim- inary validation of the tool}

By applying on experimental data the TTBS01 procedure with the calculation prescribed in [10], the results in terms of statistical distribution of $e_{s}$, i.e. the relative error on braking distance, as defined in (1)), were unsatisfactory, as visible in Figure 9: only $60 \%$ of the simulated test runs were able to satisfy the precision requirements, even considering a measured value of $e_{s}$ of $5.5 \%$.

To reduce the statistical dispersion with respect to experimental data, some additional features were introduced in the simulation tool. Since the aim of the software tool was to perform a calculation of braking performances according EN14531, we initially tried to maintain the original structure of the proposed method, simply by adding the possibility of considering in the calculation a variable tabulated brake pad friction factor. The idea was to verify how a small variation of the friction factor, which is assumed constant by the method proposed by EN14531, should affect the dispersion between experimental data and numerical results. There is a wide set of works in the literature [20],[21],[22],[23] concerning an accurate modeling of the complex phenomena affecting the friction factor between pads and discs, which depends on many factors, including speed, distribution and value of clamping forces/pressures, dissipated power and energy, thermal (e.g. initial temperature) and cooling conditions (e.g. 'Wet' and 'Dry' tests). It is worth to recall also that, mainly for reason of industrial and economic opportunity, the pads for a railway vehicle are often supplied at least by two different manufacturer. As a consequence it is quite common the case in which pads provided by different suppliers are installed on the same vehicles. In this work we tried to consider an approach as simpler as possible, as the most optimal trade-off between a very accurate modeling and the necessity of a simple and robust approach, which is followed by braking calculation standards. As a consequence we implemented a simplified tabulated relationship between the simulated friction factors of pads with respect to vehicle speed and loading condition of the train, mainly for the following reasons:

- Observing experimental data, it was evident an increase of the braking deceleration at low speed, $v<30 \mathrm{~km} / \mathrm{h}$ ). This phenomena is quite common in railway practice and should be caused by an increase of the friction factor for speed values lower than $20-30 \mathrm{~km} / \mathrm{h}$. In particular, an increased value of pad friction factor for lower speed is also recognizable in the example of Figure 10, which has been derived from technical documentation of the pads. More in general, the same phenomenon is quite common and is frequently observed [23],[24] on experimental tests performed for the brake pads approval according to[19].

- The population of braking tests considered in this work was quite small and exhibited a dependency with respect to different loading conditions (VOM, TSI, CE) of about $1-2 \%$ in terms of stopping distances, as defined by regulation in forces. These light perturbations on results could be simulated by introducing a small variation of the pad friction factor, which 
reflects the effect of different loading conditions, in terms of of braking forces, dissipated power and energy.

- Other secondary factors should have partially influenced the test results, e.g. the pneumatic brake calibration testing condition variations, aging of pads, temperature, etc., considering the limitations arising during the normal management of testing activities, e.g. the availability of the line, the activities that should be performed to change the loading conditions of the train,etc..

As a consequence, using data from the friction material manufacturer and a narrower population of tests on the train (four braking tests over a population of 50), a simplified feasible behavior of pad friction factor was identified. It is shown in Figure 11, as a function of the two parameters: traveling speed $v$ and loading condition of the train, since the clamping forces of the brakes are selfregulated with respect to vehicle weight and traveling speed, fixing the mean values of clamping forces respect to the dissipated power.

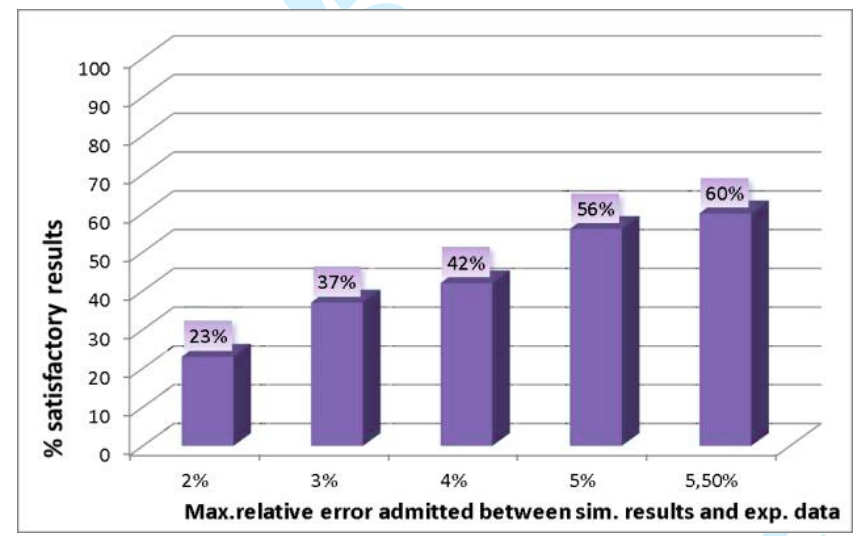

Figure 9: Number of satisfactory simulation results as a function of the acceptable value of $e_{s}$ (constant brake pad friction factor). 
Pad Friction Factor

Figure 10: Pad friction factor behavior, some curves from the technical documentation provided by the supplier of brake pads.

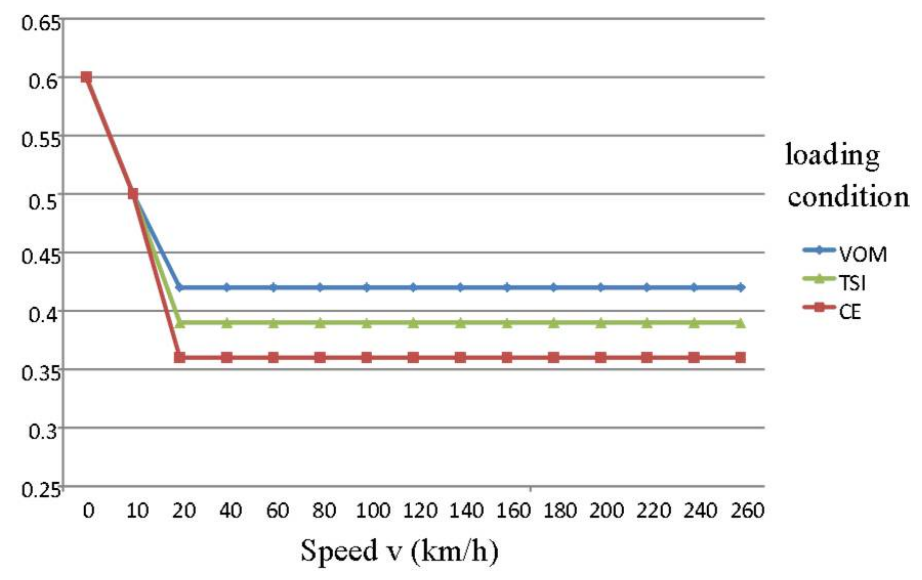

Figure 11: Variable braking pad friction factor implemented on TTBS01 for the validation on EMU V250 experimental data. 
Modifying the software TTBS01 and implementing the proposed brake pad behavior, which is parameterized over three-four points, the obtained results were much better and the criteria for the software validation were satisfied considering an acceptable value of $e_{s}$ lower than $5.5 \%$ (exactly $5.35 \%$ ), as shown in Figure 12. It's also interesting to notice that, more in general, with the modifications introduced, the number of elements which respect a threshold of $2 \%-3 \%$ and $4 \%$ of precision is more than doubled.

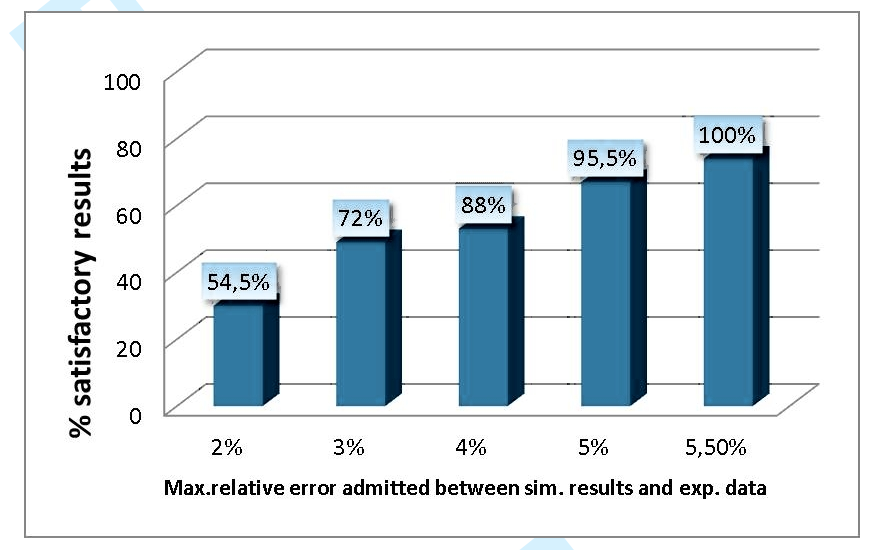

Figure 12: Number of satisfactory simulation results as a function of the admissible value of $e_{s}$ (variable pad friction factor is implemented).

Finally as visible in Figure 13 and in Figure 14, where the first ten braking test simulation and experimental results are compared, there is also a general good fitting-agreement in terms of shape and behavior of speed profiles. In particular the results shown Figure 13 and Figure 14 are referred to emergency braking maneuvers performed in the VOM loading condition (vehicle tare), repeated twice in both the sense of motion over the line. 


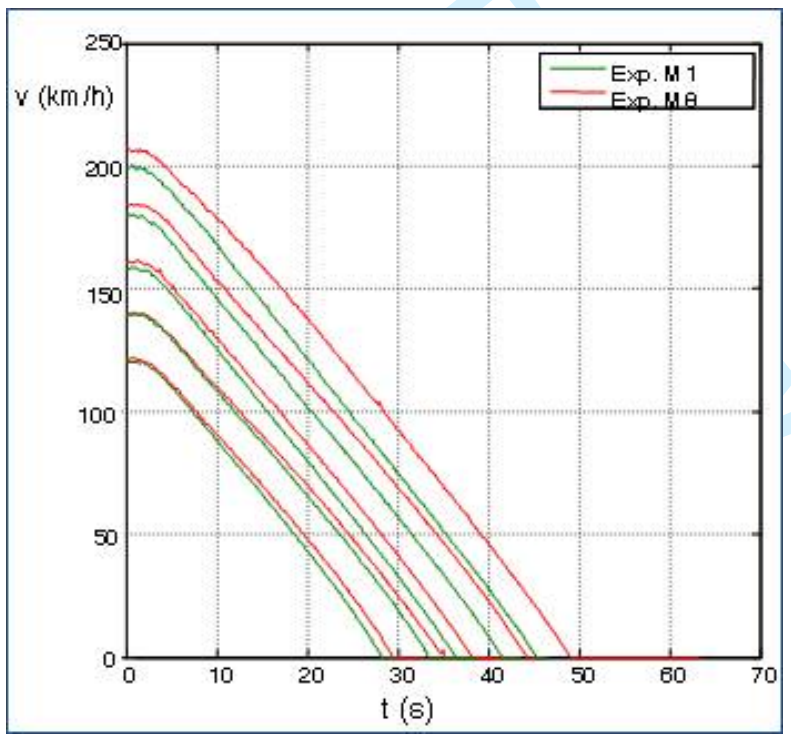

Figure 14: Experimental speed profiles measured on ten braking test runs, with different brake entry speeds and motion sense, with emergency braking. 


\section{Conclusions}

Preliminary validation of the developed TTBS01 tool on EMU V250 experimental data provided encouraging feedbacks. TTBS01 can be considered both a good tool for the preliminary simulation of braking systems and a base to build up real-time code for the monitoring of brake performances. Feedback from validation activities performed on EMUV250 showed that the obtained results are quite sensitive with respect to the brake pad friction factor considered for the calculation of braking performances. As a consequence the implementation of an optional feature to model a variable pad friction factor have proved to be useful to obtain a better fitting of experimental data. In the current version of the TTBS01 tool the variability of pad friction factor is implemented only with respect to vehicle speed and loading conditions. The implementation of a more sophisticated friction model able to consider, as example, pads initial temperature or cooling conditions should lead to even more precise results. However it should be also pointed out that in order to exploit a potential improvement coming from a more advanced calculation, an accurate choice of input data and parameters should be carefully performed.

\section{Acknowledgments}

The authors wish to thank all the workers of AnsaldoBreda that directly and indirectly participated to this project, for their competence and their cooperative approach which significantly helped the positive conclusion of the activity.

\section{References}

[1] Technical specification for interoperability relating to the rolling stock subsystem of the trans-European high-speed rail system referred to in Article 6(1) of Council Directive 96/48/EC. 30/05/2002.

[2] M. Malvezzi, P. Presciani, B. Allotta, and P. Toni. "Probabilistic analysis of braking performance in railways". Proceedings of the Institution of Mechanical Engineers, Part F: Journal of Rail and Rapid Transit, 217(3), 149-165.

[3] Malvezzi M., Pugi L., Papini S., Vettori G., Conti L. and Tesi S, Models of High Speed Train Emergency Braking Deceleration for the Definition of Automatic Train Protection Intervention Curves, Proceedings of the First International Conference on Railway Technology: Research, Development and Maintenance, April 2012 Las Palmas, Gran Canaria

[4] Pugi L., Malvezzi M., Allotta B., Banchi L. and Presciani P., A parametric library for the simulation of a Union Internationale des Chemins de Fer (UIC) pneumatic braking system, Proc. Instn. Mech. Engrs. Vol. 218 Part F: J. Rail and Rapid Transit, IMechE 2004 pag 117-132 
[5] Piechowiak T., Pneumatic train brake simulation method, Vehicle System Dynamics International Journal of Vehicle Mechanics and Mobility vol.47, No. 12, pp. 1473-1492

[6] Cantone L. , TrainDy: the new Union Internationale des Chemins de Fer software for freight train interoperability, Proc. IMechE, Part F: J. Rail and Rapid Transit, 2011, 225 (F1), 57-70. DOI 10.1243/09544097JRRT347

[7] Pugi L., Malvezzi M., Tarasconi A., Palazzolo A., Cocci G., Violani M., Simulation of WSP Systems on MI-6 Test rig, Vehicle system Dynamics, Vol. 44, Supplement 2006, pp.843-852

[8] Pugi L.,Allotta B., Hardware-In-the-Loop Testing of On-Board Subsystems: Some Case Studies and Applications, Railway Safety, Reliability, and Security: Technologies and Systems Engineering, pp. 249-280

[9] Pugi L., Conti L. Braking Simulations of Ansaldo Breda EMU V250. In proceeding of IAVSD 2009, pp. 904-911

[10] EN14531 Railway applications, Methods for calculation of stopping and slowing distances and immobilisation Edition: 2009-09-15

[11] AnsaldoBreda, 2010/a, OBVT50 Brake performance test - Vehicle type test procedure - EMUV250 14/05/2010

[12] AnsaldoBreda, 2010/b, OBVT50 Brake performance test - Vehicle type test procedure - Test Report 22/11/2010

[13] EN 15734-1 Railway applications - Braking systems of high speed trains -Part 1: Requirements and definitions November 2010

[14] UIC 544-1 Freins - Performance de freinage, 4th edition, October 2004

[15] UIC B 126/DT 414 UIC B 126 /DT 414 (June 2006), Methodology for the safety margin calculation of the emergency brake intervention curve for trains operated by ETCS/ERTMS

[16] ERRI,2004 ERRI B 126/DT 407, (3rd draft November 2004), Safety margins for continuous speed control systems on existing lines and mi-gration strategies for ETCS/ERTMS

[17] L.Pugi, A.Rindi, A.Ercole, A.Palazzolo, J.Auciello, D.Fioravanti, M.Ignesti (2011). Pre-liminary studiesconcerning the application of dif-ferent braking arrangements on italian freights trains. VEHICLE SYSTEM DYNAMICS, vol. 8, p. 1339-1365, ISSN: 0042-3114

[18] L.Pugi, A.Rindi, A.Ercole, A.Palazzolo, J.Auciello, D.fioravanti, M.Ignesti (2009). Attivi-tà di studio esimulazione per l'introduzione del regime di locomotiva lunga. INGEGNERIA FERROVIARIA, vol. 10, p.833-852, ISSN: 0020-0956 
[19] UIC 541-3, 2010, Brakes-Disc Brakes and their application, General Conditions for the approval of Brake Pads, 7th edition, July 2010

[20] Y. Desplanquesa O. Roussettea, G.Degallaixa, R. Copinb, Y. Berthierc, "Analysis of tribological behaviour of pad disc contact in railway braking: Part 1. Laboratory test development, compromises between actual and simulated tribological triplets" Volume 262, Issues 5/6, 28 February 2007, Pages $582-591$

[21] H.S. Qi, , A.J. Day, "Investigation of disc/pad interface temperatures in friction braking" Volume 262, Issues 5/6, 28 February 2007, Pages 505/513

[22] P Dufrénoy "Two-/three-dimensional hybrid model of the thermomechanical behaviour of disc brakes" 2004 218: 17Proceedings of the Institution of Mechanical Engineers, Part F: Journal of Rail and Rapid Transit

[23] F Cartigny, P Dufrénoy and B Desmet, "A thermal analysis of a new railway brake concept using liquid cooling", 2004 218: 79Proceedings of the Institution of Mechanical Engineers, Part F: Journal of Rail and Rapid Transit

[24] P. Presciani, M. Rinchi, L. Pugi "Banchi per la certificazione dei componenti frenanti" Ingegneria Ferroviaria, 2003 pp. 285/294

[25] L. Pugi, M. Rinchi, "A test Rig for Train Brakes", 3rd AIMETA International Tribology Conference, AITC, Salerno - Italy 18 - 20 September 2002. 


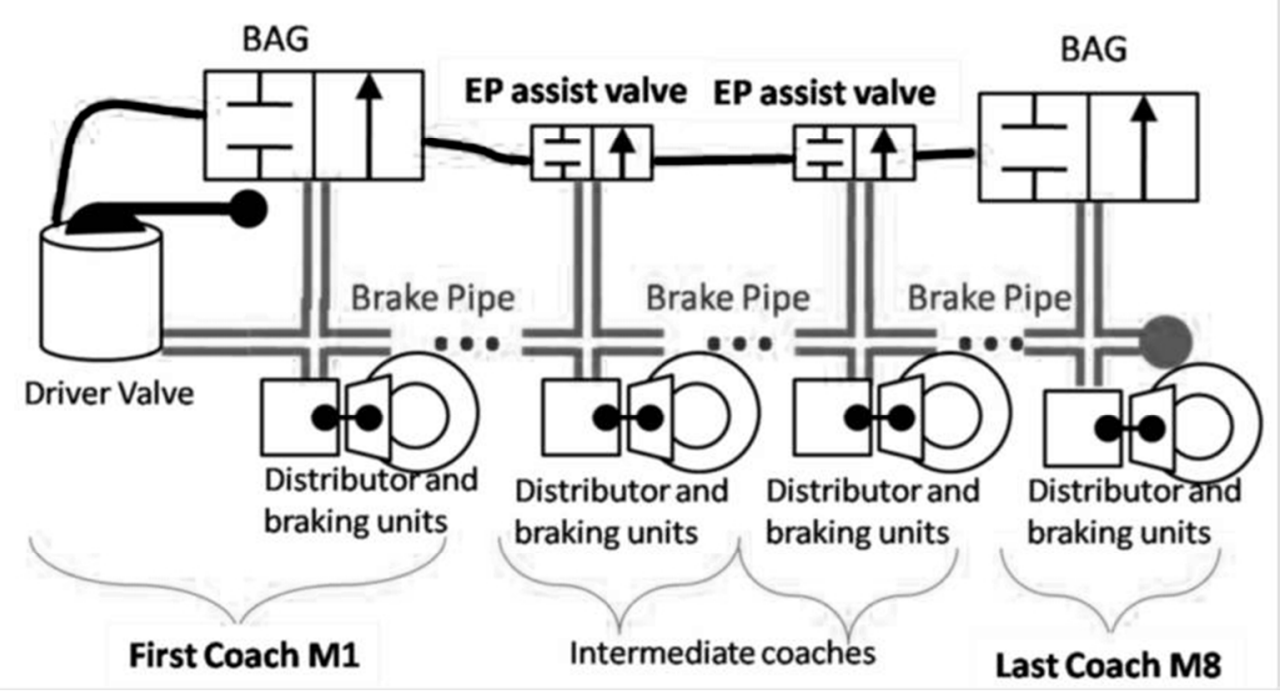

$145 \times 77 \mathrm{~mm}(150 \times 150 \mathrm{DPI})$ 


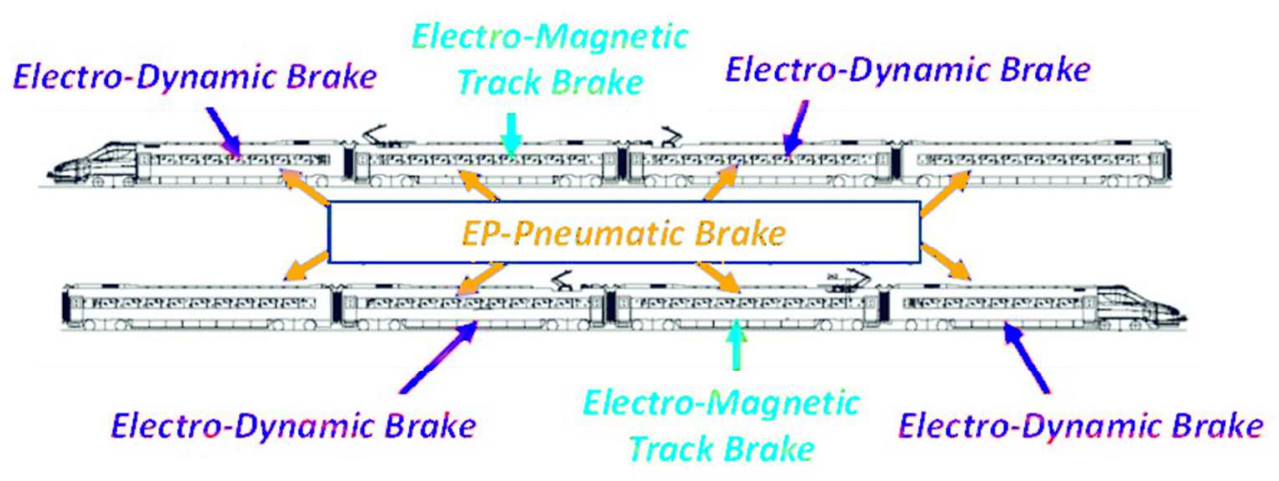

$153 \times 58 \mathrm{~mm}(150 \times 150 \mathrm{DPI})$ 


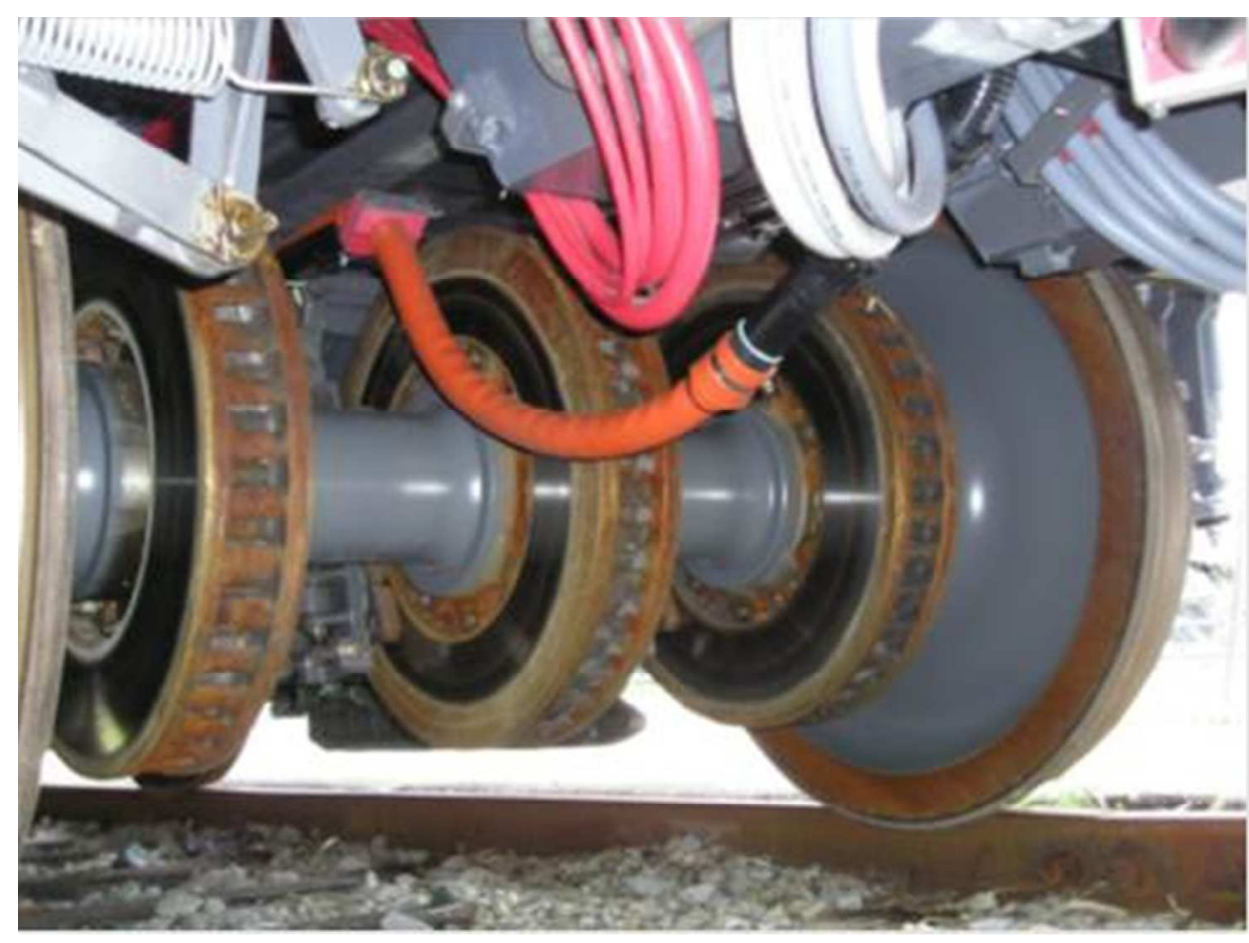

$80 \times 59 \mathrm{~mm}(150 \times 150$ DPI $)$ 


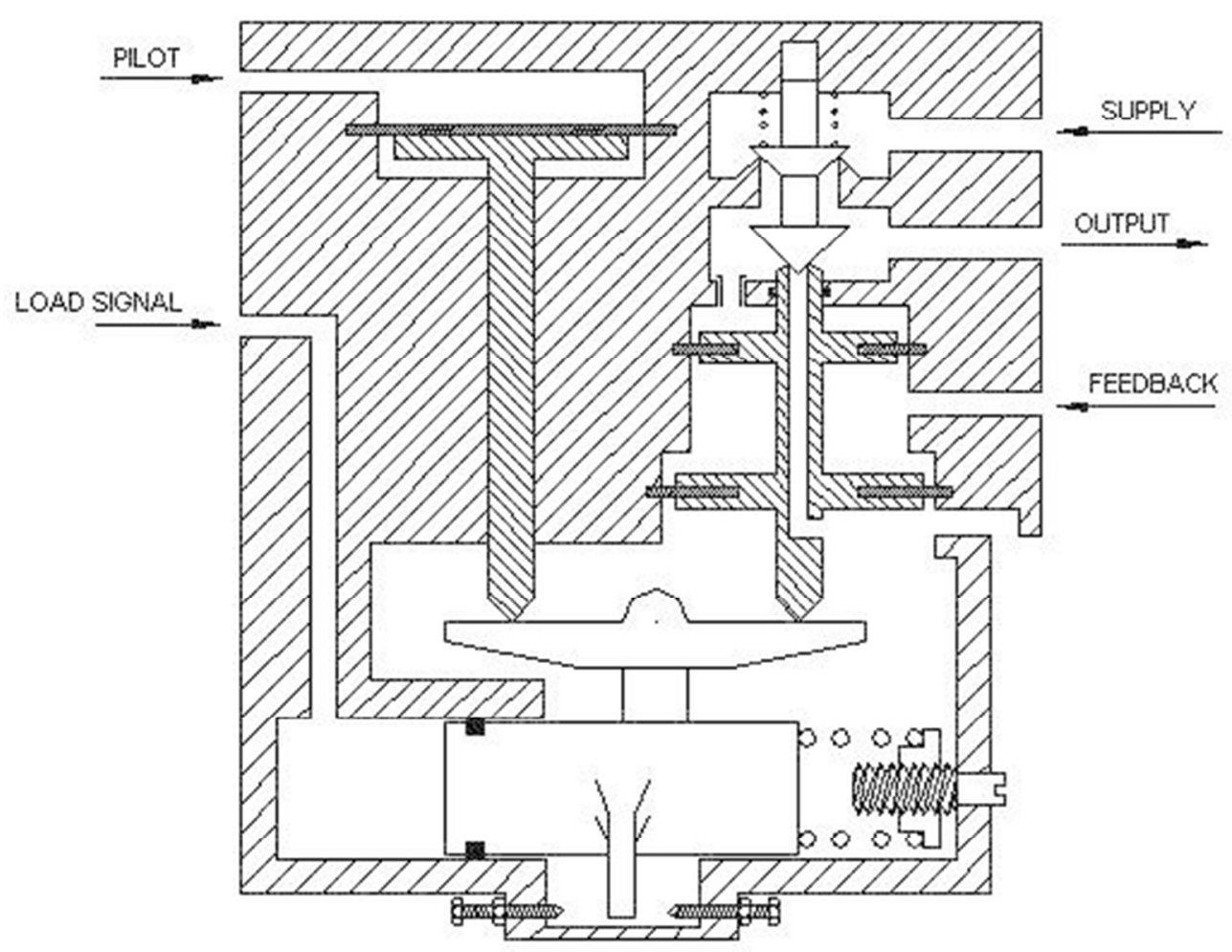

$111 \times 86 \mathrm{~mm}(118 \times 118 \mathrm{DPI})$ 


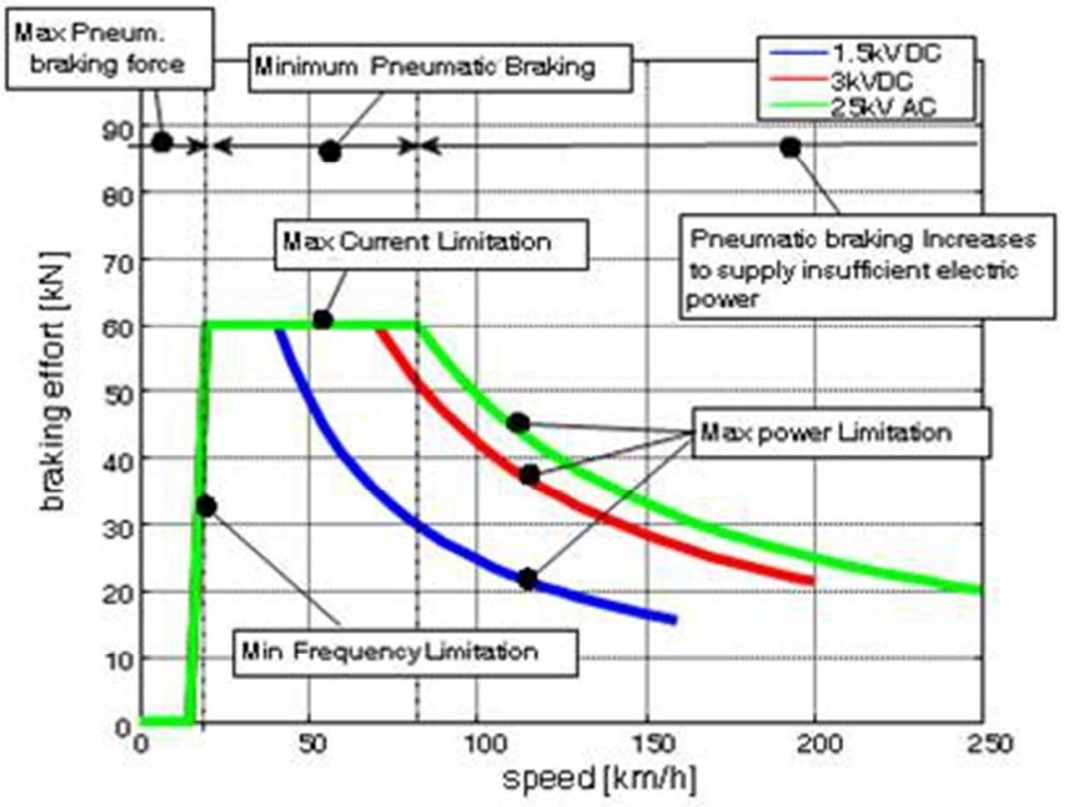

$254 \times 190 \mathrm{~mm}(42 \times 42 \mathrm{DPI})$ 
- Unit configuration

- Load condition (axle and bogie)

- Wheel

- Disc Brake (actuator,calliper,disc,time)

- Electrodynamic brake

- Magnetic brake

- Suspension

$144 \times 116 \mathrm{~mm}(150 \times 150$ DPI $)$ 

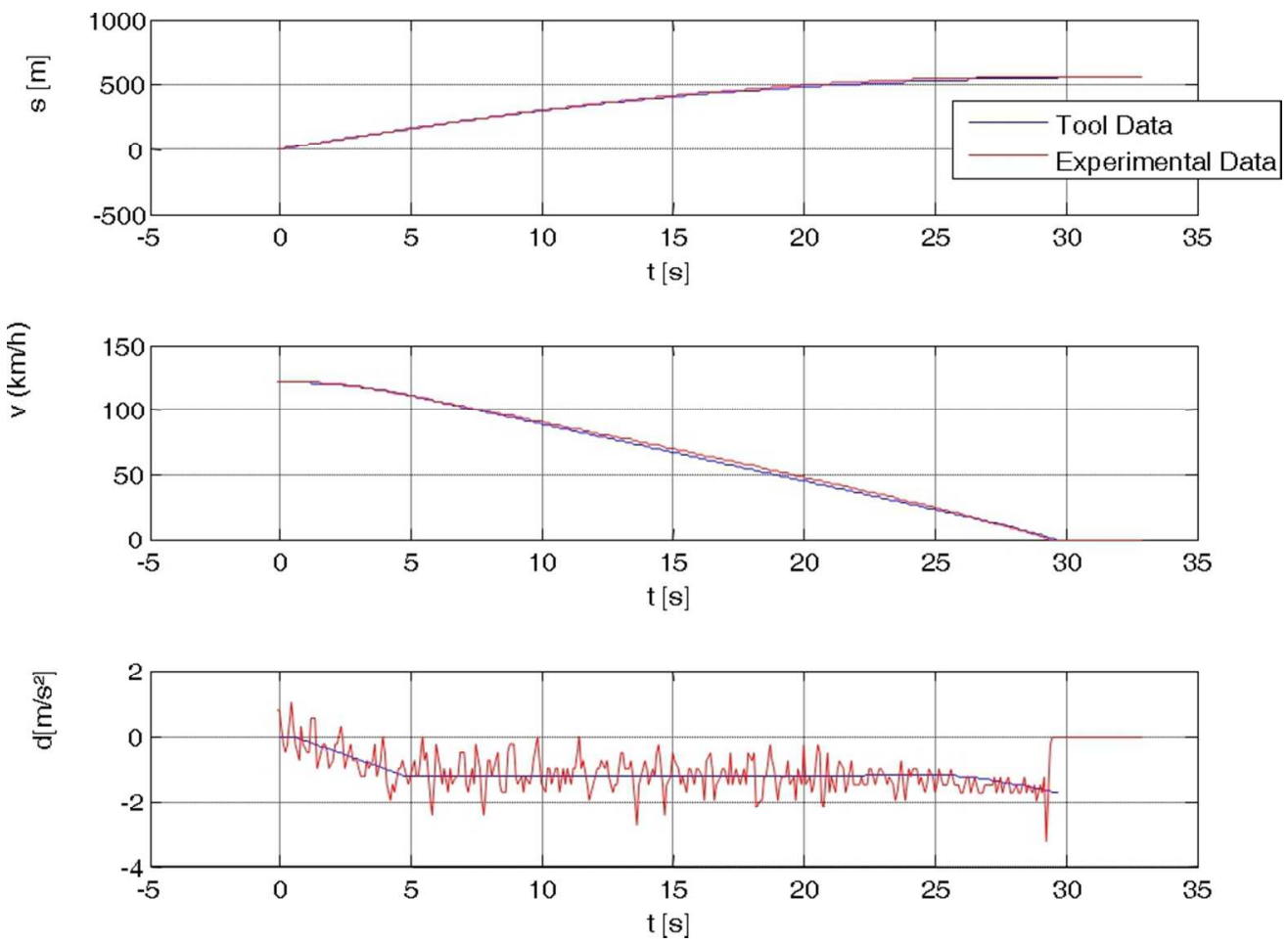

269×196mm (96 x 96 DPI) 
1

2

3

4

5

6

7

8

9

10

11

12

13

14

15

16

17

18

19

20

21

22

23

24

25

26

27

28

29

30

31

32

33

34

35

36

37

38

39

40

41

42

43

44

45

46

47

48

49

50

51

52

53

54

55

56

57

58

59

60

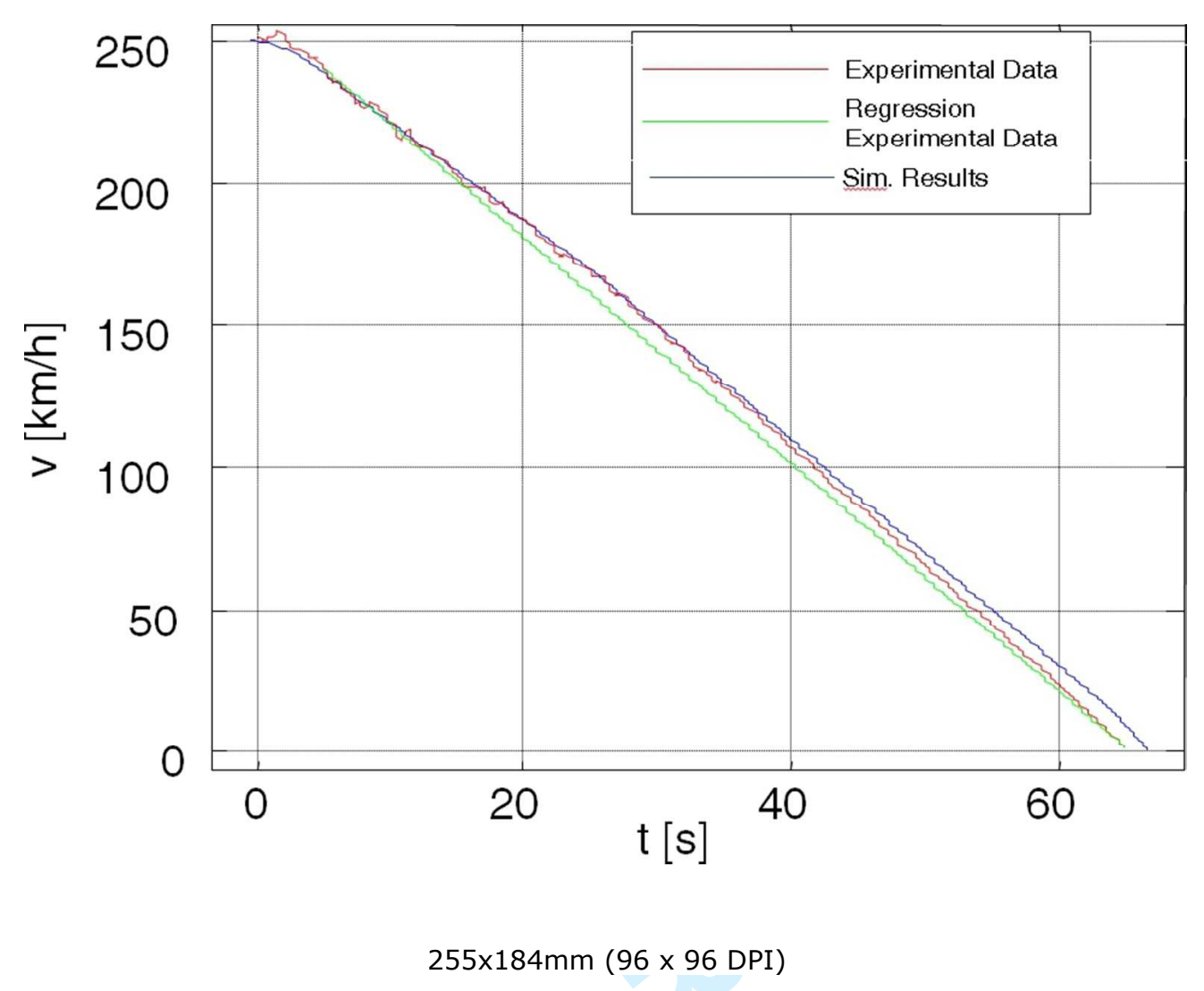

http://mc.manuscriptcentral.com/JRRT 


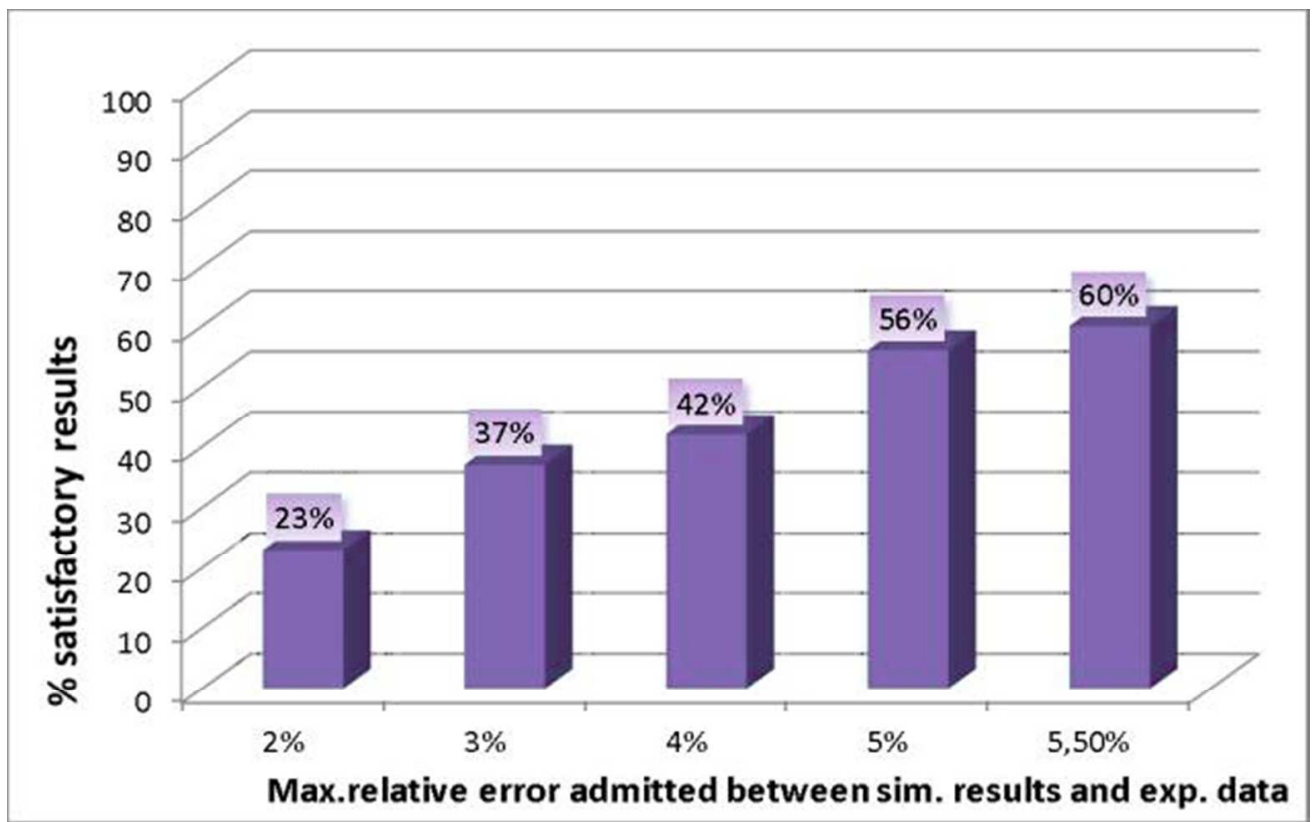

$73 \times 46 \mathrm{~mm}(220 \times 220$ DPI $)$ 


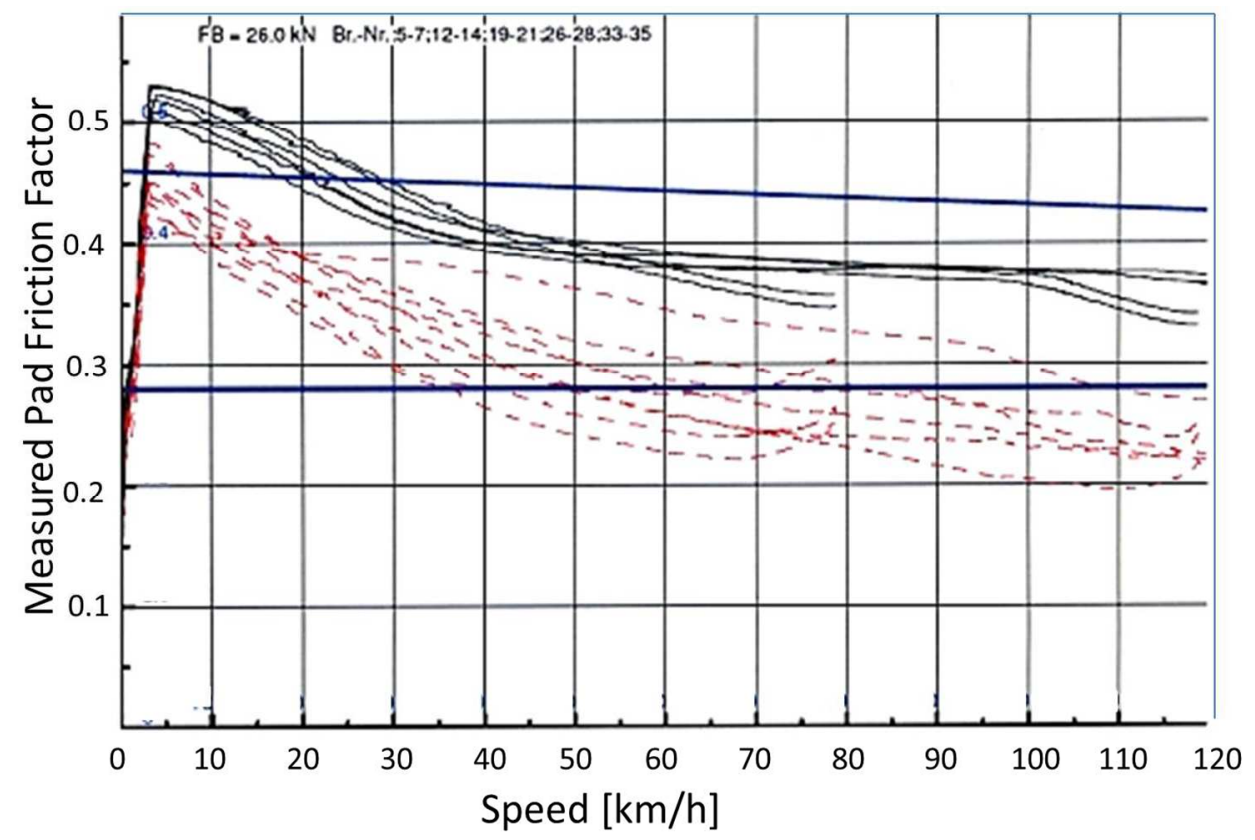

$252 \times 165 \mathrm{~mm}(150 \times 150 \mathrm{DPI})$ 


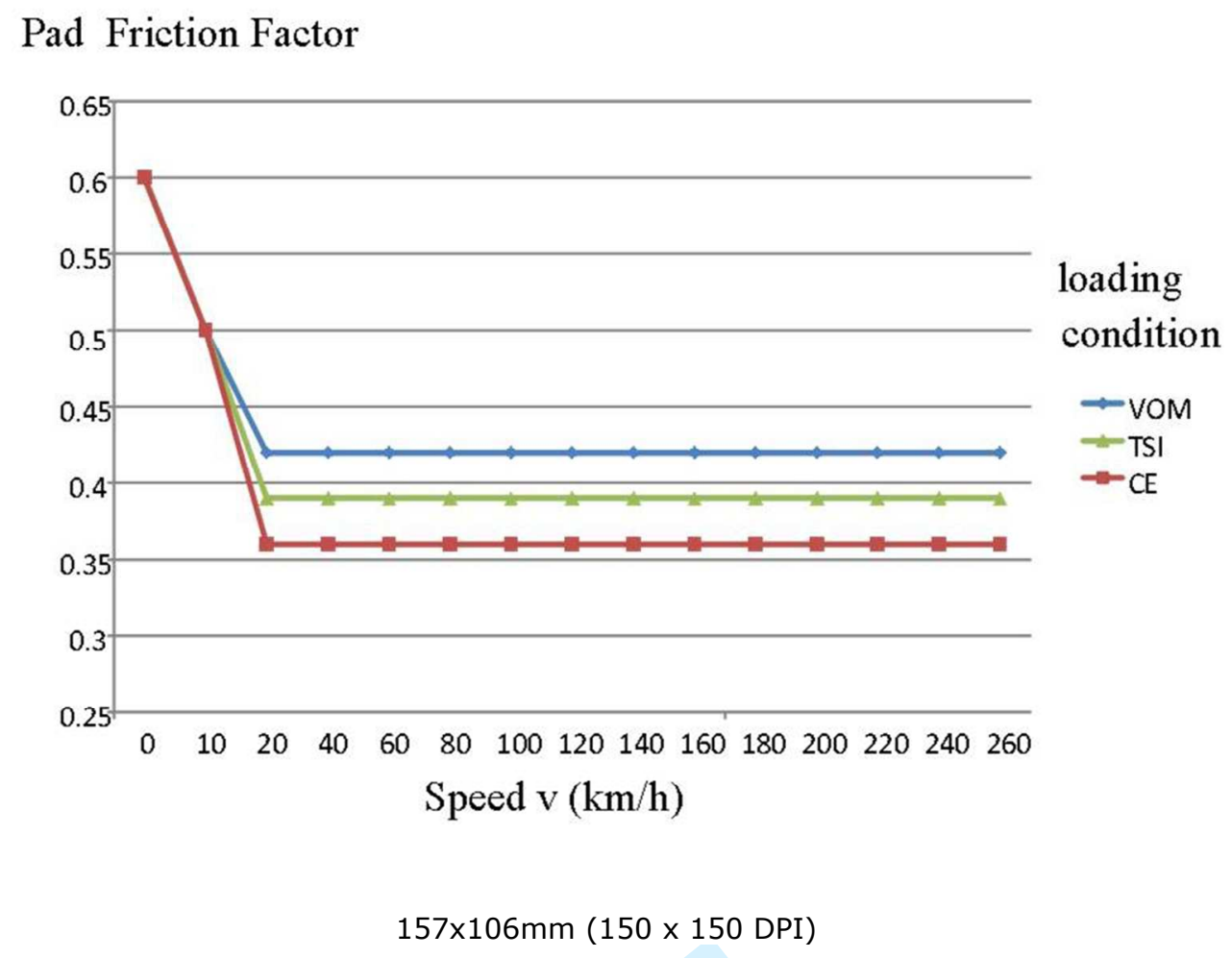




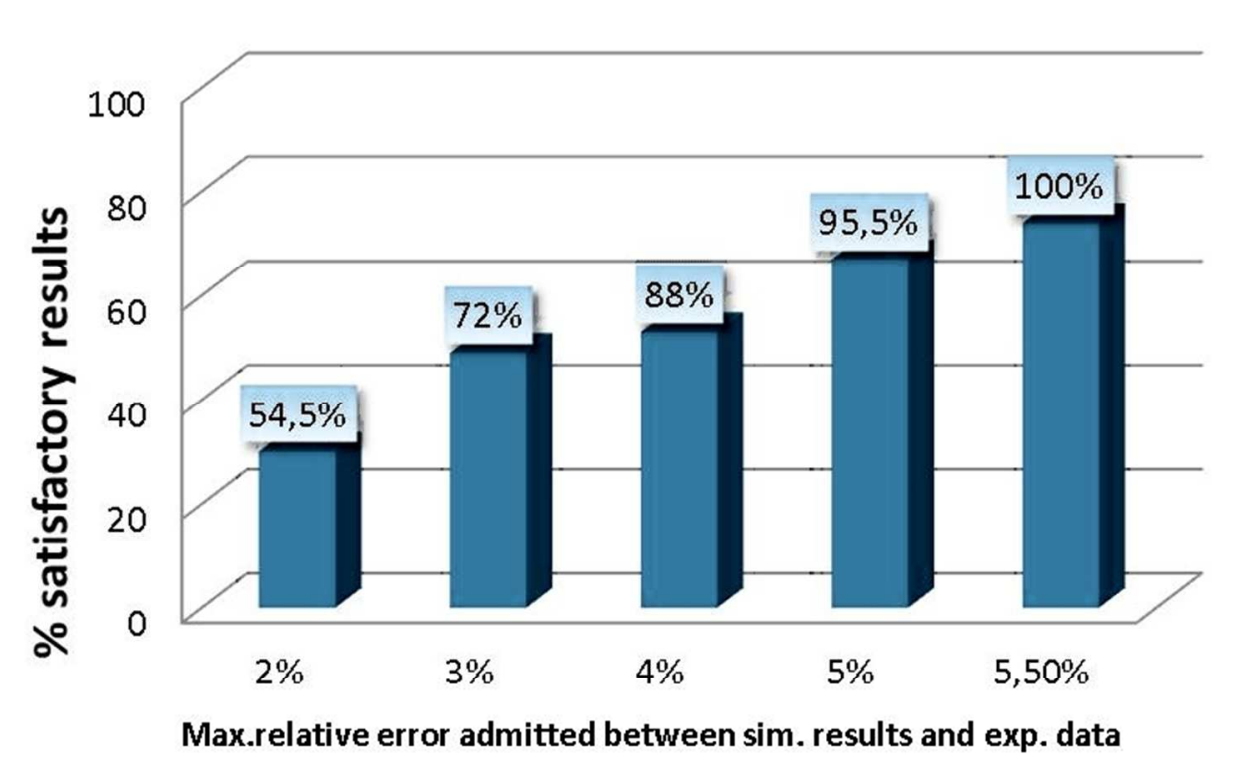

Max.relative error admitted between sim. results and exp. data 


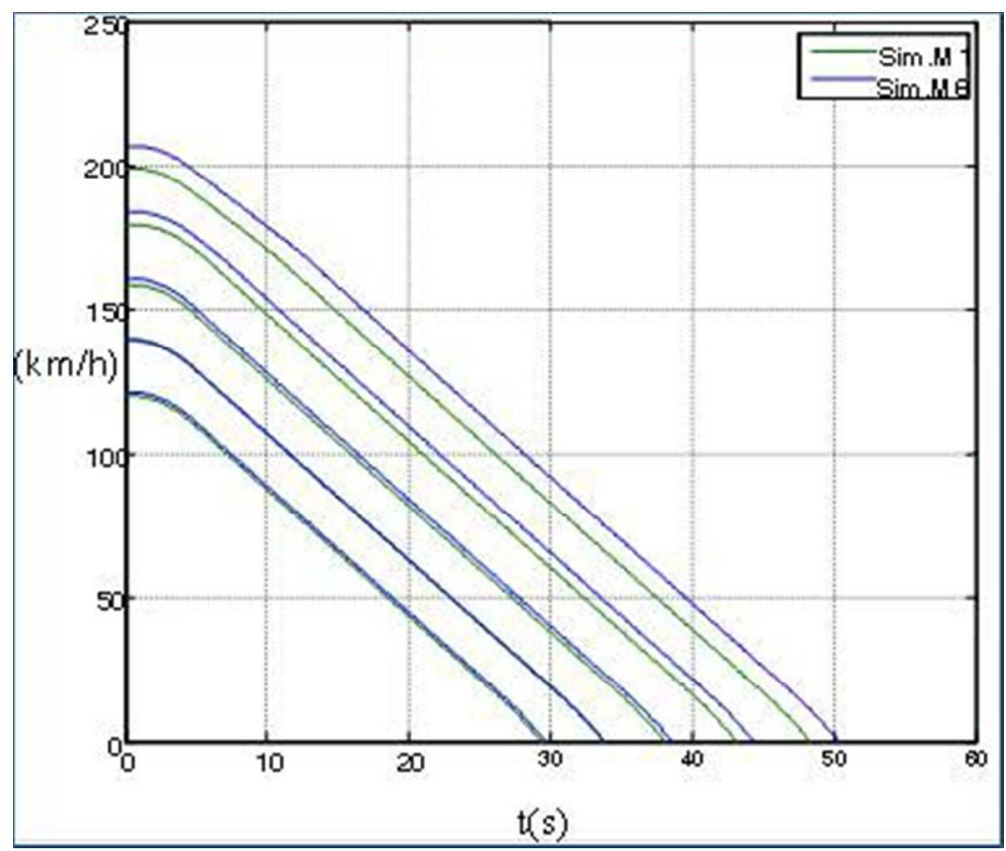

$64 \times 54 \mathrm{~mm}(150 \times 150 \mathrm{DPI})$ 


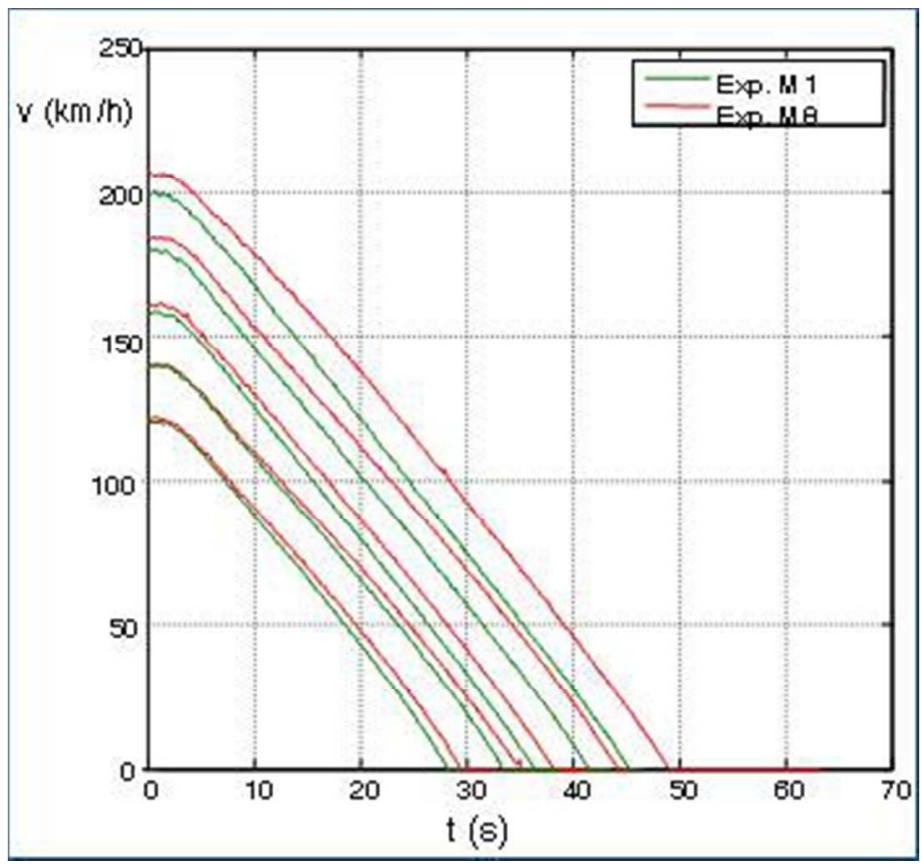

$59 \times 55 \mathrm{~mm}(150 \times 150 \mathrm{DPI})$ 